\title{
Cluster and TC-1 observation of magnetic holes in the plasma sheet
}

\author{
W. J. Sun ${ }^{1,2}$, Q. Q. Shi ${ }^{1}$, S. Y. Fu ${ }^{3}$, Z. Y. Pu ${ }^{3}$, M. W. Dunlop ${ }^{4}$, A. P. Walsh ${ }^{5}$, Q. G. Zong ${ }^{3}$, T. Xiao ${ }^{1}$, C. L. Tang ${ }^{1}$, \\ H. Reme ${ }^{6,7}$, C. Carr ${ }^{8}$, E. Lucek ${ }^{8}$, and A. Fazakerley ${ }^{5}$ \\ ${ }^{1}$ Shandong Provincial Key Laboratory of Optical Astronomy and Solar-Terrestrial Environment, School of Space Science and \\ Physics, Shandong University at Weihai, Weihai, China \\ ${ }^{2}$ State Key Laboratory of Space Weather, Center for Space Science and Applied Research, Chinese Academy of Sciences, \\ Beijing, China \\ ${ }^{3}$ Institute of Space Physics and Applied Technology, Peking University, Beijing, China \\ ${ }^{4}$ Rutherford Appleton Laboratory, Didcot OX11 0QX, UK \\ ${ }^{5}$ Mullard Space Science Laboratory, University College London, Holmbury St. Mary Dorking, Surrey RH5 6NT, UK \\ ${ }^{6}$ Université de Toulouse, UPS-OMP, IRAP, Toulouse, France \\ ${ }^{7}$ CNRS; IRAP, 9 Av. colonel Roche, BP 44346, 31028 Toulouse cedex 4, France \\ ${ }^{8}$ Space and Atmospheric Physics, the Blackett Laboratory, Imperial College, London, UK
}

Correspondence to: Q. Q. Shi (sqq@ pku.edu.cn)

Received: 28 March 2011 - Revised: 28 December 2011 - Accepted: 23 February 2012 - Published: 26 March 2012

\begin{abstract}
Magnetic holes with relatively small scale sizes, detected by Cluster and TC-1 in the magnetotail plasma sheet, are studied in this paper. It is found that these magnetic holes are spatial structures and they are not magnetic depressions generated by the flapping movement of the magnetotail current sheet. Most of the magnetic holes (93\%) were observed during intervals with $B_{\mathrm{Z}}$ larger than $B_{\mathrm{x}}$, i.e. they are more likely to occur in a dipolarized magnetic field topology. Our results also suggest that the occurrence of these magnetic holes might have a close relationship with the dipolarization process. The magnetic holes typically have a scale size comparable to the local proton Larmor radius and are accompanied by an electron energy flux enhancement at a $90^{\circ}$ pitch angle, which is quite different from the previously observed isotropic electron distributions inside magnetic holes in the plasma sheet. It is also shown that most of the magnetic holes occur in marginally mirror-stable environments. Whether the plasma sheet magnetic holes are generated by the mirror instability related to ions or not, however, is unknown. Comparison of ratios, scale sizes and propagation direction of magnetic holes detected by Cluster and TC-1, suggests that magnetic holes observed in the vicinity of the TC-1 orbit $\left(\sim 7-12 R_{\mathrm{E}}\right)$ are likely to be further developed than those observed by Cluster $\left(\sim 7-18 R_{\mathrm{E}}\right)$.
\end{abstract}

Keywords. Magnetospheric physics (MHD waves and instabilities; Plasma sheet)

\section{Introduction}

Magnetic holes (MHs) were first detected in the solar wind (Turner et al., 1977). They are observed as depressions in the magnetic field magnitude with durations of seconds to tens of seconds (Turner et al., 1977; Xiao et al., 2010; Zhang et al., 2009). Their scale sizes are often tens to hundreds of proton Larmor radii (Winterhalter et al., 1994; Zhang et al., 2008; Tsurutani et al., 2011). The criteria used by Winterhalter et al. (1994) and Zhang et al. (2008) to find magnetic holes were that the amplitude depression $\left(B_{\min } / B\right)$ is smaller than 0.5 and 0.75 , respectively. Turner et al. (1977) also defined those magnetic holes with little or no change in the magnetic field direction as linear magnetic holes (LMHs) and Winterhalter et al. (1994) found that the ambient plasma parameters of observed LMH trains, which are defined as at least two comparable linear magnetic holes in a $300 \mathrm{~s}$ interval, and LMHs were marginally mirror stable. They therefore suggested that LMHs are probably the remnants of mirror modes structures in the solar wind (see also Winterhalter et al., 1995; Russell et al., 2008; Zhang et al., 2008, 2009). Many other mechanisms have been proposed to explain the magnetic holes in the solar wind, such as the soliton approach (Baumgartel, 1999; Baumgartel et al., 2003), and theories associated with Alfvén waves (see, for example, Buti et al., 2001; Tsurutani et al., 2005). The stable solitons correspond to isotropic plasma with high $\beta$ and their propagation direction is close to perpendicular to the ambient magnetic field vector. 
It is well-known that the mirror instability (Hasegawa, 1969; Southwood and Kivelson, 1993) could occur in a high $\beta$ anisotropic plasma with the perpendicular temperature higher than the parallel temperature, while the ion cyclotron mode could also occur under these conditions (Davidson and Ogden, 1975). The difference between them are that the ion cyclotron mode propagates parallel to the ambient magnetic field with a frequency smaller than ion cyclotron frequency, while the mirror mode propagates obliquely to the background magnetic field vector with zero phase velocity relative to plasma flow (Gary et al., 1976; Southwood and Kivelson, 1993). Génot et al. (2001) pointed out that the growth rate of ion cyclotron mode can overcome the mirror mode in a plasma with high temperature anisotropy $\left(T_{\text {perp }} / T_{\text {par }}\right)$. Therefore, the occurrence of the mirror mode is most likely in a high $\beta$ and low anisotropy plasma. Most of the theoretical work referred to above assumed cold background electrons. However, ions and electrons are all expected to contribute to the mirror instability (Gary and Karimabadi, 2006). When the electron temperature is comparable to the ion temperature, the effects of electrons cannot be neglected anymore (Pokhotelov et al., 2000; Istomin et al., 2009). The electrons could affect the threshold of mirror instability and also the scale size of magnetic holes, but not very significantly. Recent observations have also shown that the trapped ions could be heated at intermediate pitch angles and cooled at small parallel velocities in the trough of nonlinear mirror mode structures (Soucek and Escoubet, 2011).

As ions can be heated in the perpendicular direction by the quasi-perpendicular bow shock (Liu et al., 2005), mirror mode structures are observed in the corresponding terrestrial magnetosheath (Kaufmann et al., 1970; Crooker et al., 1979; Tsurutani et al., 1982) and in the terrestrial cusp (Shi et al., 2009a). Observations and numerical simulations have shown that magnetic peaks are rarely seen in mirror stable plasma because of their rapid decay, but magnetic holes could survive in a mirror stable plasma. Therefore, both peaks and holes could be observed in the magnetosheath, and most holes are observed near the magnetopause, where the plasma is mirror stable (Baumgartel et al., 2003; Travnicek et al., 2007; Soucek et al., 2008; Génot et al., 2009).

Mirror mode structures are reported to be observed in other regions, e.g. close to Io (Russell et al., 1999), in the vicinity of comets (Russell et al., 1987), in the magnetosheaths of other planets (Bavassano Cattaneo et al., 1998; Volwerk et al., 2008a) and even in the induced magnetosphere of Venus (Volwerk et al., 2008b). Mirror mode structures were first detected in the terrestrial magnetosphere during storm times (Hasegawa, 1969). Rae et al. (2007) reported a series of drift mirror mode structures in the dawn side magnetosphere and believed the observations were an example of the mirror instability excited ULF waves. Most of the above observations in the magnetosphere were interpreted as drift mirror mode structures, and often could drive pulsations in the magnetic field (Cheng and Qian, 1994). The drift mirror instability also adheres to the same threshold conditions as the mirror instability. The convected mirror mode is a standing mode, while the drift mirror instability becomes oscillation with frequency equal to the particle drift wave frequency (Hasegawa, 1969; Pokhotelov et al., 2001; Rae et al., 2007). However, Hellinger (2008) pointed out that the threshold of the mirror instability, in the case of one cold species, is not applicable for the drift mirror instability.

A series of magnetic holes, which were deemed mirror mode structures, were observed by THEMIS-D (P3) between two dipolarization events in the plasma sheet (Ge et al., 2011). The THEMIS-D spacecraft was located at about $11 R_{\mathrm{E}}$ close to the equatorial plane and local midnight tail region at that time. Their results implied that dipolarization might promote the generation of mirror mode structures. The mirror mode structures reported in the article were likely to be already in the nonlinear phase, because the minimum magnetic field magnitude inside the holes was lower than $50 \%$ of the background field magnitude. Moreover, the width of these mirror mode structures is less than one proton Larmor radius, but at tens of electron gyroscales ( $\mathrm{Ge}$ at al., 2011).

In this paper, we use the data from Cluster during its 2003 tail season and Double Star TC-1 during its 2004 tail season to investigate magnetic holes in the plasma sheet. The apogee of Cluster is about $19 R_{\mathrm{E}}$ and the apogee of TC-1 is about $12 R_{\mathrm{E}}$. The $\mathrm{X}$ location of the THEMIS-D event used by Ge et al. (2011) is about $11 R_{\mathrm{E}}$. We investigated plasma sheet magnetic holes with the four spacecrafts of Cluster and also TC-1. We examined their electron properties and will discuss their possible formation mechanism. We also compared our results with those of $\mathrm{Ge}$ et al. (2011) and will discuss the possible relationship between the magnetic holes detected by Cluster, TC-1 and THEMIS.

Below, we first introduce the procedure we used to find magnetic holes. We then show their spatial features and confirm them by an estimate of the direction of boundary motion. The characteristics of the background magnetic field of these magnetic holes and their scale sizes are shown as well.

\section{Cluster and TC-1 observations}

In this section, we study the magnetic holes detected by Cluster and TC-1 in the plasma sheet. We used data obtained from the Flux Gate Magnetometer (FGM) (Balogh et al., 2001), Plasma Electron and Current Experiment (PEACE) (Johnstone et al., 1997), and Cluster Ion Spectrometry Experiment (CIS) (Rème et al., 2001) instruments onboard Cluster. We also used data from Flux Gate Magnetometer (FGM) (Carr et al., 2006) and Hot Ion Analyzer (HIA) (Rème et al., 2005) instruments onboard TC-1. Proton moments were calculated from the CIS-CODIF sensor onboard C1, while electron moments were obtained from the PEACE instrument onboard $\mathrm{C} 2$. Both proton and electron moments were calculated on 
(a)

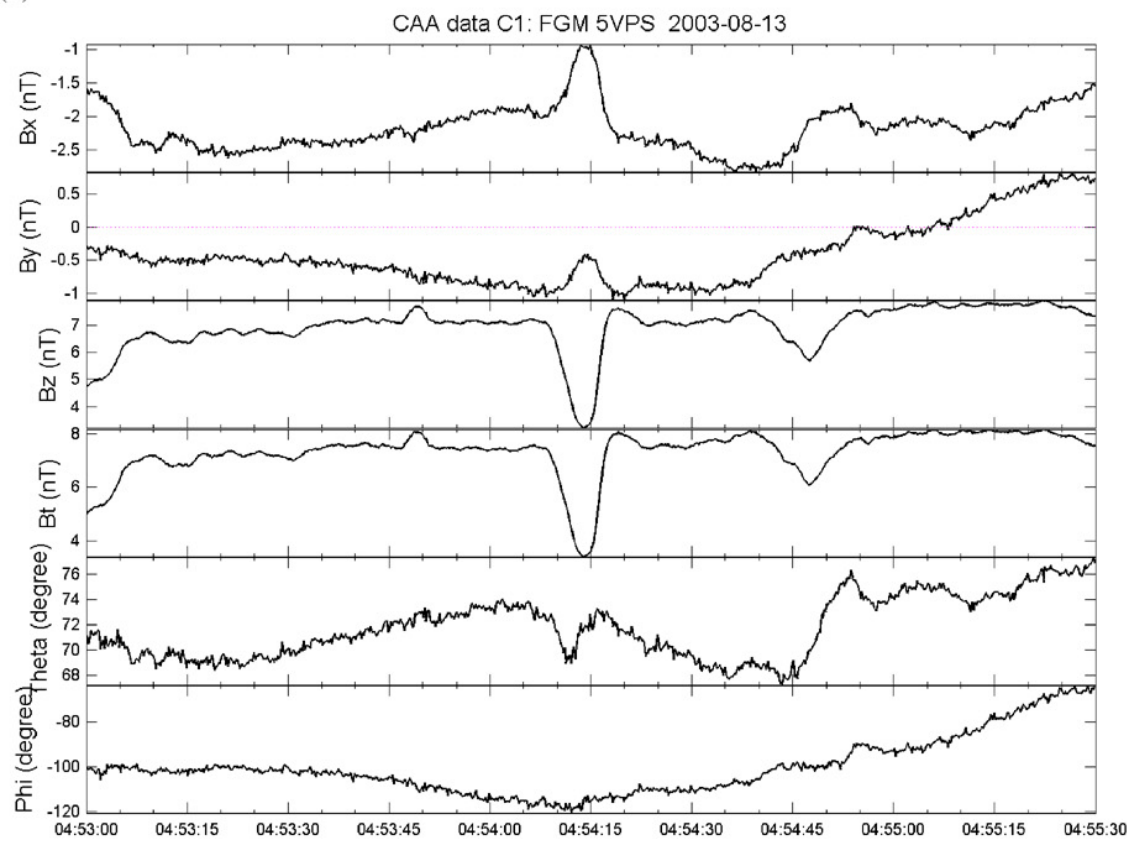

(b)

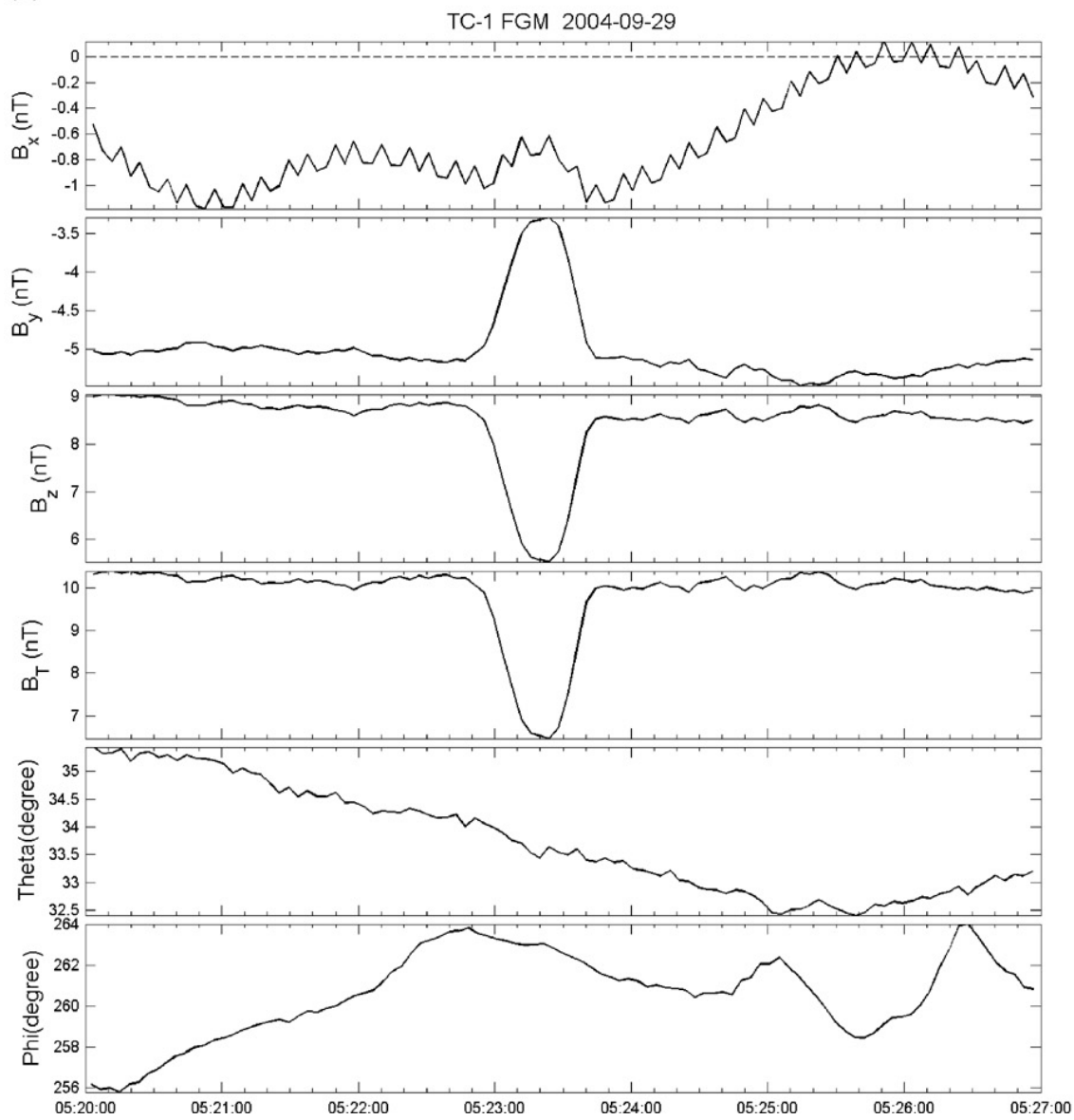

Fig. 1. (a) A magnetic hole observed by Cluster. (b) A magnetic hole observed by TC-1. From top to bottom panels: the GSM X component of magnetic field; Y component; Z component; the magnetic field magnitude; the polar angle; the azimuthal angle. 

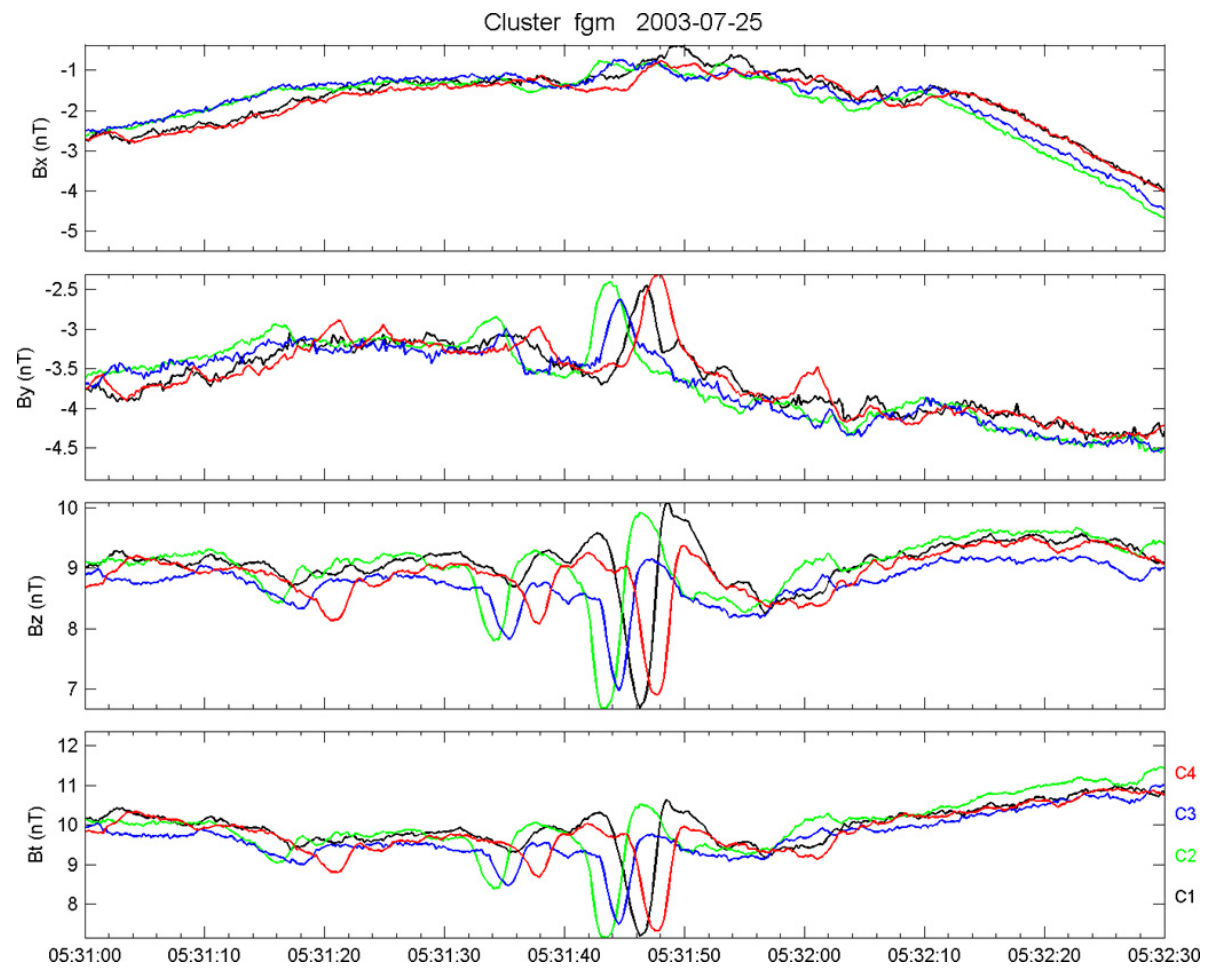

Fig. 2. From top to bottom panels: The GSM X component; Y component; Z component of magnetic field; the magnetic field magnitude.

Table 1. Timing velocities of the two boundaries of magnetic holes in Fig. 2.

\begin{tabular}{ccccccc}
\hline Date & Selected time & $\mathrm{V}\left(\mathrm{km} \mathrm{s}^{-1}\right)$ & $N_{\mathrm{x}}$ & $N_{\mathrm{y}}$ & $N_{\mathrm{z}}$ & Angle \\
\hline 25 Jul 2003 & $05: 31: 40-05: 31: 48$ & 49.1155 & 0.08 & -0.86 & -0.50 & $8.74^{\circ}$ \\
25 Jul 2003 & $05: 31: 46-05: 31: 50$ & 51.4859 & 0.21 & -0.81 & -0.55 & \\
\hline
\end{tabular}

the ground from the observed 3-D particle distributions. In our analysis, the velocity data were taken from the Cluster HIA instrument, and the proton temperature and density were taken from the CODIF sensor. We also used electron pitch angle distributions measured using a combination of the LEEA and HEEA sensors. Ion moments from TC-1 HIA were calculated onboard.

\subsection{Observation overview}

Similar to Xiao et al. (2010), Winterhalter et al. (1994) and Zhang et al. $(2008,2009)$, the ratio, $B_{\min } / B$ and the directional change angle, $\varpi$ are used to identify magnetic holes. $B_{\min }$ is the minimum field magnitude inside a magnetic hole and $B$ is the average field magnitude in a given time interval centered on the magnetic hole (300 s in the references above). The directional change angle $(\varpi)$ is the angle between the magnetic field vectors at the two boundaries of a magnetic hole. Zhang et al. (2008, 2009) and Xiao et al. (2010) chose a ratio, $B_{\min } / B$ of no more than 0.75 and a directional change angle $\varpi$ no more than $15^{\circ}$ to identify linear magnetic holes, while Winterhalter et al. (1994) used a ratio $B_{\min } / B$ of no more than 0.5 and directional change angle $\varpi$ no more than $5^{\circ}$ as their criteria. Here, in this paper we use $B_{\min } / B<0.75$, $\varpi<15^{\circ}$ to search for magnetic holes in the plasma sheet. Because the magnetic field in the plasma sheet is much more inhomogeneous than that in the solar wind, we use a time interval of $90 \mathrm{~s}$ to calculate $B$ rather than $300 \mathrm{~s}$. In this paper, we will use Cluster magnetic field data sampled at 5 vectors per second and TC-1 magnetic field data at spin (4s) resolution.

The plasma sheet encompasses the magnetotail current sheet and the flapping of the current sheet is frequently observed (Sergeev et al., 2004; Sun et al., 2010). This flapping often results in a spacecraft repeatedly crossing the tail current sheet, during which a reduction in magnetic field magnitude could be observed. It is easy to distinguish current sheet crossings from magnetic holes as the $\mathrm{X}$ component of magnetic field reverses direction in the tail current sheet. But there can also be magnetic depressions caused by current sheet flapping where the tail current sheet is not fully 
(a)

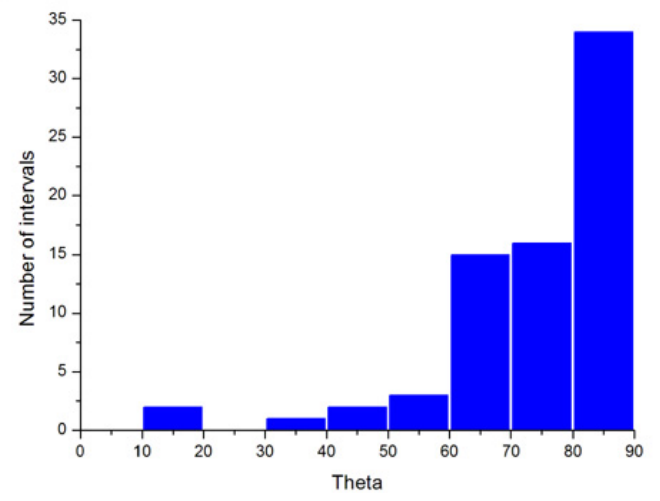

(c)

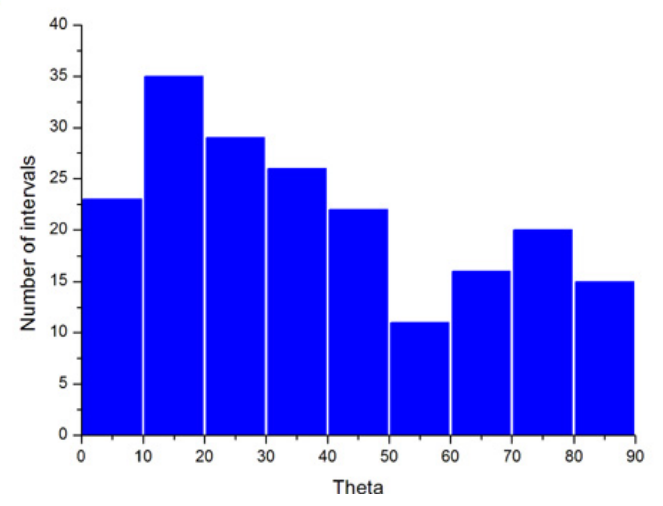

(b)

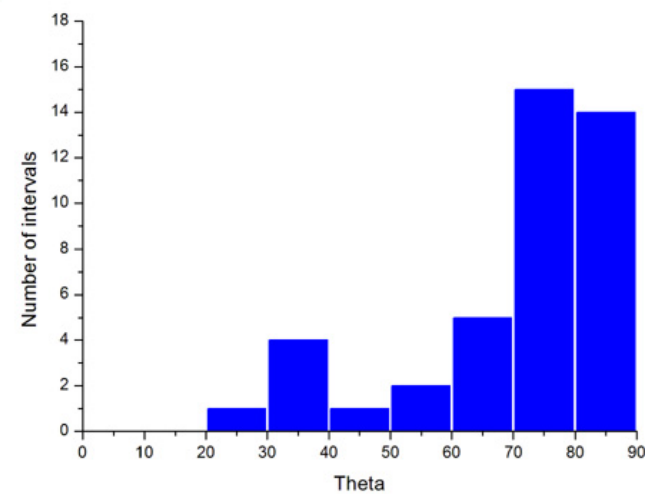

Fig. 3. (a), (b) The histograms for the magnetic field elevation angle ( $\operatorname{atan}\left(B_{\mathrm{Z}} / B_{\mathrm{X}}\right)$ ) of the magnetic holes detected by Cluster and TC-1. The $B_{\mathrm{Z}}$ and $B_{\mathrm{X}}$ are their background magnetic field in the GSM coordinate system. (c) The histogram for magnetic field elevation angle of randomly selected Cluster plasma sheet passes.

traversed. Inside the magnetic depression the directional angle of the field is expected to change considerably if the depression is caused by a close current sheet encounter. Sperveslage et al. (2000) once investigated the maximum directional angle change inside the magnetic holes and the average value was $23.4^{\circ}$. Figure $1 \mathrm{a}$ and $\mathrm{b}$ show typical magnetic holes detected by Cluster and TC-1 in the plasma sheet. From Fig. 1a we can see that the maximum directional angle change inside the structure is smaller than $4^{\circ}$, which reveals that it is not caused by the current sheet flapping motion.

After automatic selection according to these criteria, we ruled out the magnetic depressions, which may be generated by the flapping movement of the tail current sheet. We found 72 magnetic holes in Cluster 2003 tail season and 42 magnetic holes in the TC-1 2004 tail season.

\subsection{Features of magnetic holes detected by Cluster and TC-1}

\subsubsection{Spatial structures}

Figure 2 shows a magnetic hole detected by all four Cluster spacecrafts. From the "interlaced" magnetic field profiles, we can tell that the magnetic hole is a spatial structure, rather than a temporal effect (e.g. Shi et al., 2009a). This can be confirmed by considering the angle between the normals of its two boundaries. Table 1 lists the velocities of the two boundaries of this magnetic hole calculated by the timing method (see Russell et al., 1983; Paschmann and Daly, 1998, their chapters 10,11, 12, and 14). The angle between the two boundaries is about $8.74^{\circ}$, which means that the propagation directions of the two boundaries are nearly parallel to each other, and this indicates that the structure is spatial. The boundary velocities of other events that can be observed by all the four spacecrafts were calculated by the timing method or by other methods (Shi et al., 2005, 2006, 2009a, b), confirming that they are also spatial structures as well.

\subsubsection{The background magnetic field of the magnetic holes}

We calculated the background magnetic field elevation angle $(\theta)$ for each magnetic hole events detected by Cluster and TC-1 and displayed the results in Fig. $3 a$ and b, respectively. $\theta=\arctan \left(B_{\mathrm{Z}} / B_{\mathrm{x}}\right)$, in which $B_{\mathrm{Z}}$ and $B_{\mathrm{X}}$ are the background values averaged over the $90 \mathrm{~s}$ time interval in the 


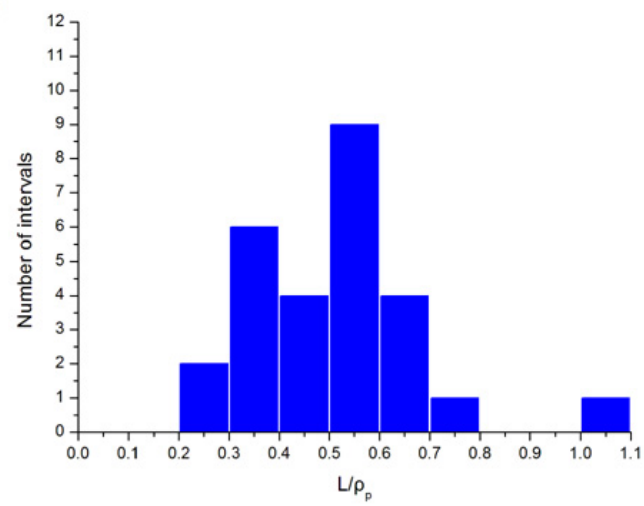

(c)

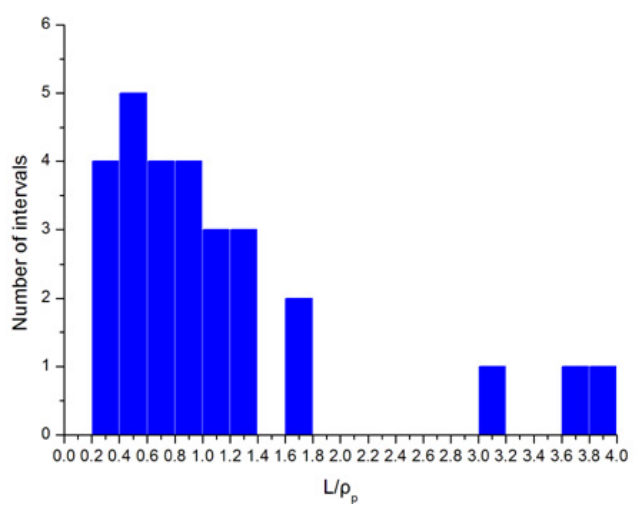

(b)

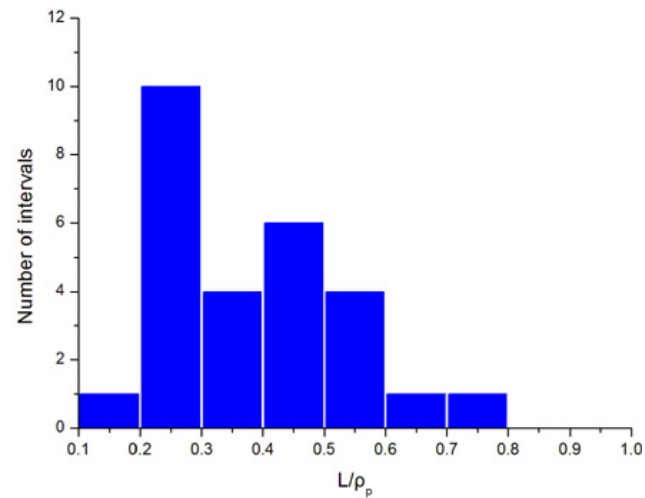

(d)

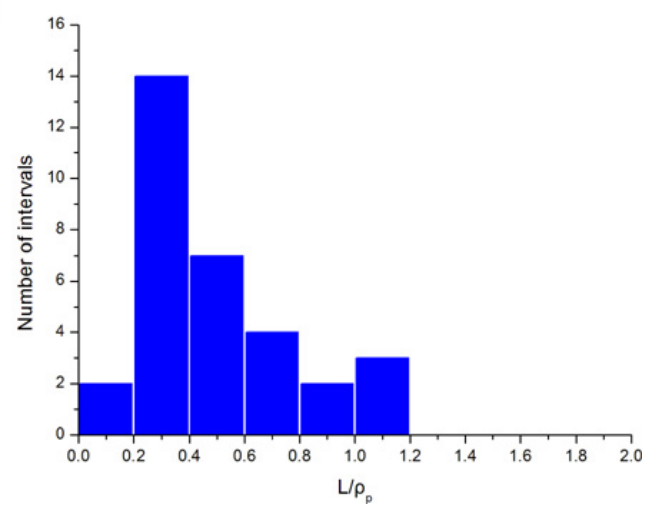

Fig. 4. Histograms of the ratios of magnetic hole scale sizes to proton Larmor radii. The proton Larmor radius is calculated from their background parameters. (a) The scale size of magnetic holes detected by Cluster calculated from timing velocity. (b) The scale size of magnetic holes detected by Cluster calculated from their background plasma flow velocity. (c) The scale sizes of magnetic holes detected by TC-1, which were calculated from their background plasma flows. (d) The same as b except that these magnetic holes were selected from Cluster spin resolution magnetic field data.

GSM coordinate system. From Fig. 3a (Cluster observation) we can see that about $93 \%(67 / 72)$ magnetic holes have a $\theta$ bigger than $50^{\circ}$, which means $B_{\mathrm{Z}}$ is bigger than $B_{\mathrm{X}}$, while this percentage amount is about $86 \%$ (36/42) in Fig. 3b (TC1 observation). Thus, most of the magnetic holes were observed when the background $B_{\mathrm{Z}}$ was much larger than $B_{\mathrm{x}}$. We also randomly selected 197 plasma sheet passes and calculated $\theta$. Figure $3 \mathrm{c}$ is a histogram of their magnetic field elevation angle distribution. From this figure we can see that $31.5 \%(62 / 197)$ of the plasma sheet passes had a $\theta$ bigger than $50^{\circ}$, smaller than the percentage for magnetic hole intervals. This result indicates that the plasma sheet magnetic holes seem to occur more often in a more dipolar magnetic field topology, which implies that these magnetic holes might have a close relationship with the dipolarization process.

\subsubsection{Scale sizes of the magnetic holes}

The distances between the four Cluster spacecrafts were relatively small $(\sim 100 \mathrm{~km})$ in 2003 , so many magnetic holes were observed by all four Cluster spacecrafts and could be analyzed using the 4 spacecraft timings method. We estimated the scale size of the magnetic holes by simply multiplying the timing velocity and the observed duration. The ratios of their scale sizes to the proton Larmor radii were also calculated, in which the proton Larmor radii were calculated based on the background plasma parameters. Figure $4 \mathrm{a}$ is the histogram of these ratios, from which we can see that most magnetic holes have scale sizes smaller than the proton Larmor radii. We also estimated the scale sizes of these magnetic holes through their background plasma flows as carried out by $\mathrm{Ge}$ et al. (2011). Both the Cluster and TC-1 HIA velocities were used. We only selected the magnetic holes that correspond to relatively smooth background plasma flows. The ratios of their scale sizes to proton Larmor radii calculated from flow data are shown in Fig. 4b (Cluster) and 4c (TC-1). The result, plotted in Fig. 4b, is similar to those in Fig. 4a, i.e. the average scale sizes calculated in different ways are almost equal. From the data we have shown here, it appears that these magnetic holes are propagating together with the plasma flow. As we mentioned above, the Cluster magnetic field data we used had a time resolution of $0.2 \mathrm{~s}$, while TC-1 

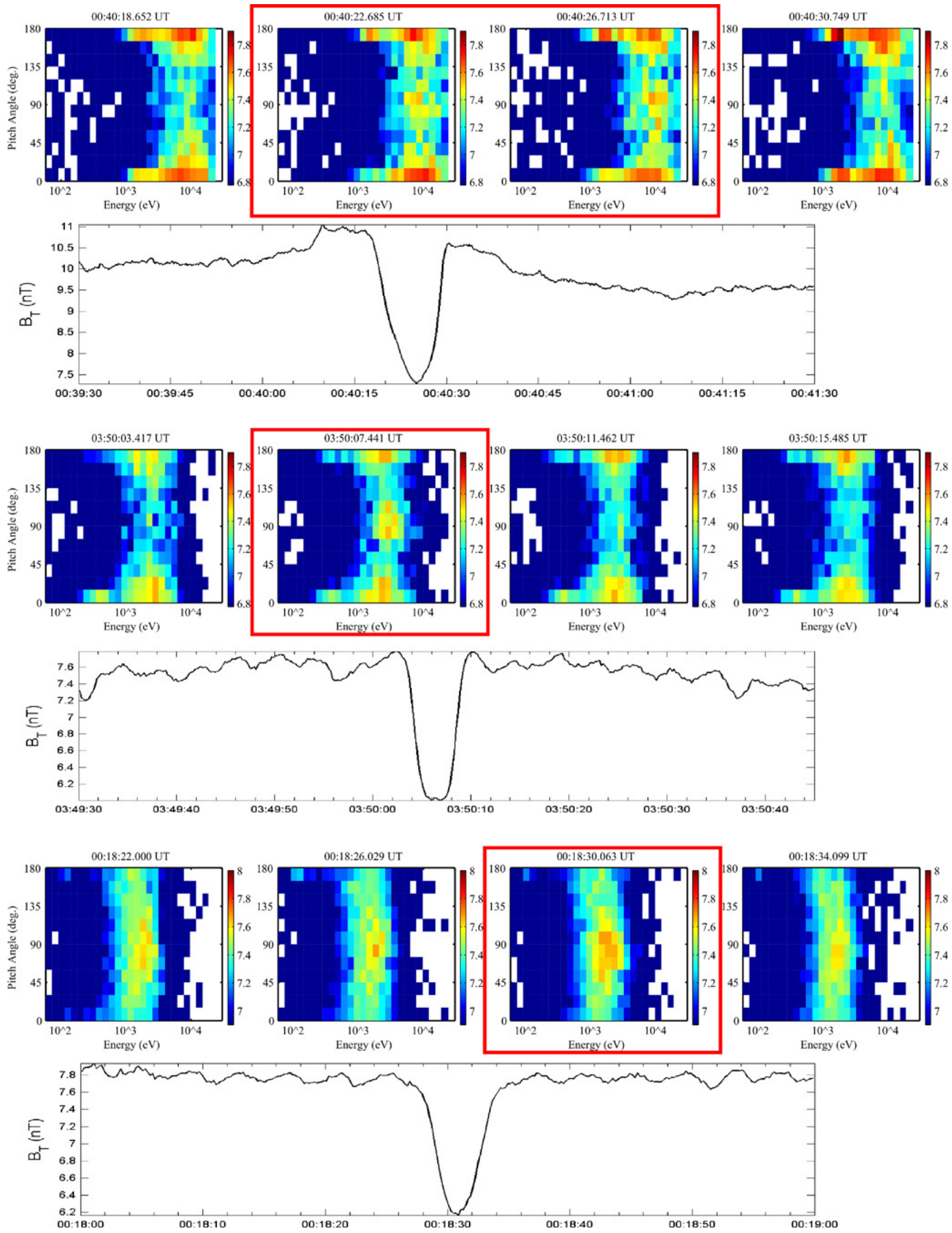

Fig. 5. Electron energy flux (unit $\log \mathrm{keV} \mathrm{cm}^{-2} \mathrm{~s}^{-1} \mathrm{sr}^{-1} \mathrm{keV}^{-1}$ ) obtained by Plasma Electron and Current Experiment (PEACE) as a function of pitch angle and energy and the related magnetic holes. The pitch angle distributions inside red frames are the distributions inside magnetic holes.

had a resolution of $4 \mathrm{~s}$. The comparison between the magnetic holes scale sizes observed by the two missions might be affected by their different time resolutions. As such, we have also selected magnetic holes using a Cluster spin $(4 \mathrm{~s})$ resolution magnetic field data, which is the same as TC-1, and calculated the ratio of their scale size to the proton Larmor radius (Fig. 4d). Even though the difference in the time resolution does have a small effect on the distribution of ratios, the magnetic holes detected by TC- 1 still seem to have relatively larger scale sizes than those found by Cluster. 


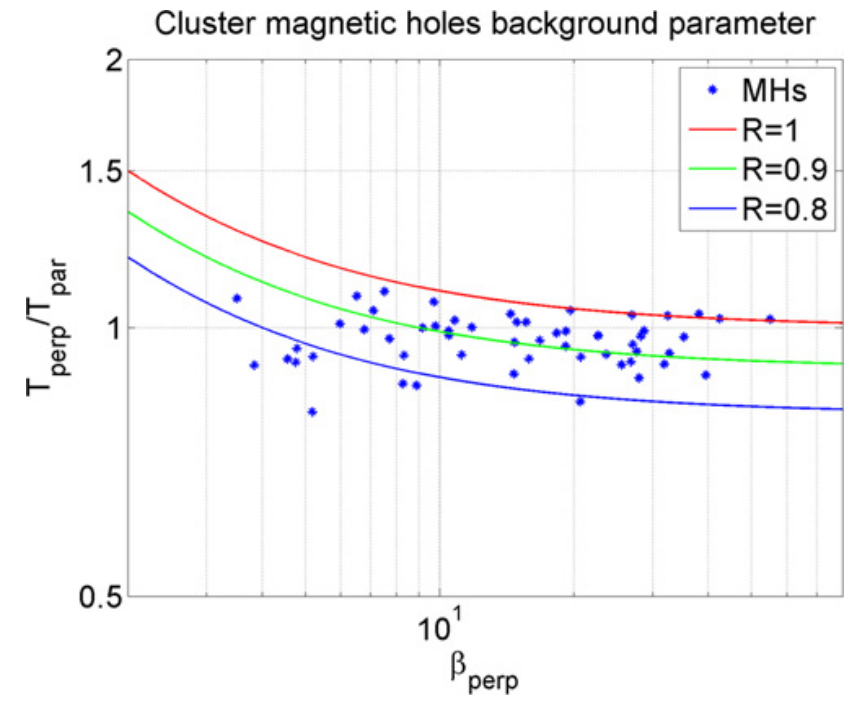

Fig. 6. The distributions of the temperature anisotropy $\left(T_{\perp} / T_{/ /}\right)$ and $\beta_{\perp}$ for magnetic holes observed by Cluster. The red line, green line, and blue line represent $R=1, R=0.9$, and $R=0.8$, respectively. We use their background temperatures and magnetic fields to calculate the $T_{\perp} / T_{/ /}$and $\beta_{\perp}$.

\subsubsection{The electron properties}

Figure 5 shows 3 examples of magnetic holes in the plasma sheet and corresponding electron energy-pitch angle diagrams. We can see that the electrons inside each of the three magnetic holes have an enhancement of differential energy flux at a $90^{\circ}$ pitch angle relative to background conditions. Most magnetic holes detected by Cluster have this feature, which is quite different from the electron isotropic distribution inside the magnetic holes observed by Ge et al. (2011).

Despite the electron energy flux enhancement at a $90^{\circ}$ pitch angle inside the magnetic hole structure, we can see from the three figures (Fig. 5) that the background electron distributions are variable. The survey of Walsh et al. (2011) showed that the isotropy of the plasma sheet electron distribution varies with proton $\beta$ and electron energy. So this might be the reason for the variance of our magnetic hole background electron distributions.

We also considered whether the enhancement of electron pressure is sufficient to compensate for the decrease of magnetic field pressure inside the magnetic holes. The perpendicular temperature of electrons inside most magnetic holes is increased, which is consistent with the enhancement of electron energy flux at a $90^{\circ}$ pitch angle. The electron parallel temperature is not obviously changed in most magnetic holes, although there are some holes in which the electron parallel temperature decreased slightly (4 of 56 cases), and seldom the electron parallel temperature increased inside magnetic holes (only 1 case). Overall, in most magnetic holes, the total electron temperature increased (only 2 cases decreased). The electron density in most magnetic holes was only slightly above the background, and in some cases even decreased (only 2 cases). Statistical results show that, on average, the thermal pressure had an increase due to the enhancement of electron temperature and density, although this increase in electron pressure does not completely compensate for the reduced magnetic pressure in the magnetic holes. From the statistical results of Walsh et al. (2011), we found that the average proton energy flux is several times of the average electron energy flux, and our results also show that the proton temperature is typically many times of electron temperature (in the next section). Furthermore, our observations show that the proton pressure does not change in the magnetic holes. The total pressure, therefore, would only be affected slightly by the incomplete compensation of electron thermal and magnetic pressures and remains approximately constant.

\subsubsection{Relationship with mirror mode instability}

The criteria (cold background electron) for the mirror instability can be stated as $R=\left(T_{\perp} / T_{/ /}\right) /\left(1+1 / \beta_{\perp}\right)>1$, where $\beta_{\perp}=n k T_{\perp} /\left(B^{2} / 2 \mu_{0}\right)$ (Hasegawa, 1969; Southwood and Kivelson, 1993). Figure 6 shows distributions of $\beta_{\perp}$ and temperature anisotropy $\left(T_{\perp} / T_{/ /}\right)$of the magnetic holes for which there is CODIF data (56 of the 72 magnetic holes). These parameters are the average values calculated from the $90 \mathrm{~s}$ time interval. The horizontal coordinate in Fig. 6 represents $\beta_{\perp}$ and the vertical coordinate represents temperature anisotropy, which is equal to $T_{\perp} / T_{/ /}$. Every solid circle in Fig. 6 denotes a magnetic hole. The red, green, and blue lines in Fig. 6 represent $R=1, R=0.9$, and $R=0.8$, respectively. The region above the red line is mirror unstable, and below the line is mirror stable. From Fig. 6 we can see that $7 \%(4 / 56)$ of Cluster magnetic holes occur in the mirror unstable environment, and there are about $55 \%(31 / 56)$ of all magnetic holes that occur in a $R>0.9$ environment.

The ratios of these magnetic holes electron to ion temperatures range from 0.1 to 0.5 . We calculated the value of $T_{\perp} / T_{/ /}-1-1 / \beta_{\perp}-\left(\left(T_{\perp} / T_{/ /}-1\right)^{2} T_{\mathrm{e}}\right) /\left(2 T_{\perp}(1+\right.$ $\left.\left.T_{\mathrm{e}} / T_{/ /}\right)\right)>0$, which is the criterion for a mirror unstable condition when taking the effects of electrons into account (Istomin et al., 2009). There were also only 4 events occurring in the mirror unstable environment. The effects of the electrons on the mirror instability threshold can be neglected.

We found that 44 of all the 56 events occurred in the environment with $\beta / /$ values larger than 7 , so that here the proton mirror mode had a faster growth rate than proton cyclotron mode (Gary and Karimabadi, 2006), suggesting that the proton cyclotron mode is less likely to be responsible for the formation of the magnetic holes. 
(a)

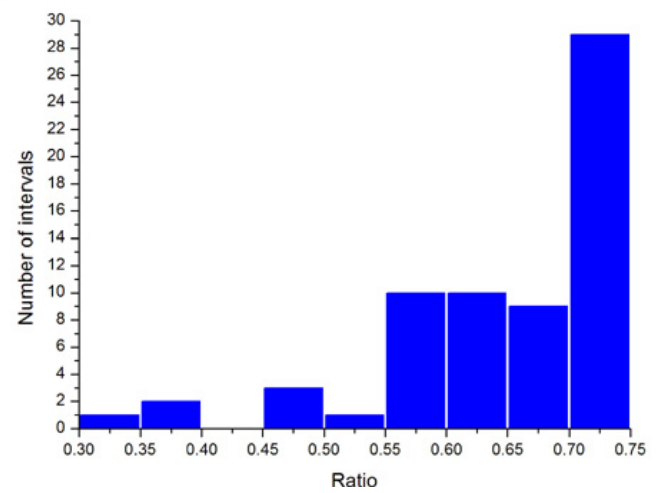

(b)

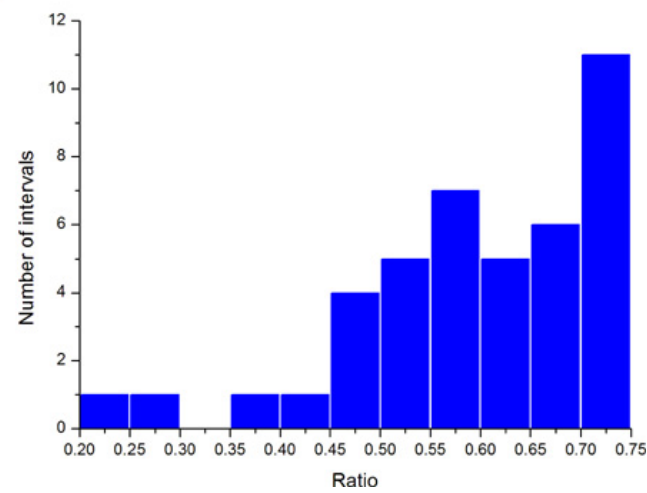

Fig. 7. The distribution of $B_{\min } / B$ ratios. (a) For magnetic holes detected by Cluster with $0.2 \mathrm{~s}$ resolution magnetic field data. (b) For TC-1 magnetic holes selected with spin resolution field data.
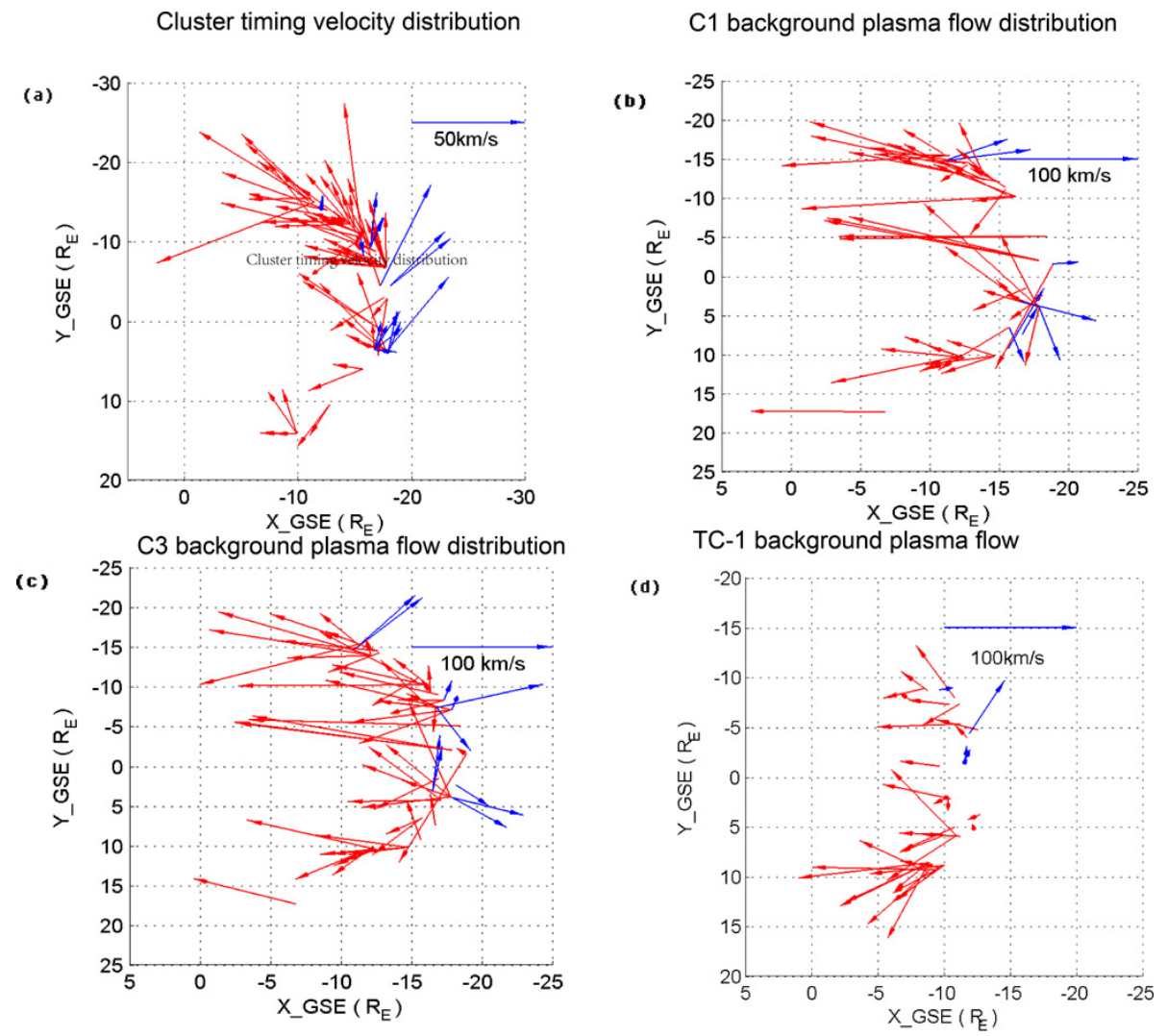

Fig. 8. (a) Distribution of timing velocities in X-Y plane of magnetic holes observed by Cluster. (b) The distribution of background plasma flow velocities observed by $\mathrm{C} 1$ in $\mathrm{X}-\mathrm{Y}$ plane. (c) The distribution of background plasma flow velocities observed by $\mathrm{C} 4$ in $\mathrm{X}-\mathrm{Y}$ plane. (d) Background plasma flow velocity distribution of magnetic holes observed by TC-1 in X-Y plane. The red lines represent magnetic holes propagating towards the Earth. The blue lines represent magnetic holes propagating tailward.

\section{Discussion and summary}

In this paper we have analyzed the magnetic holes detected by Cluster and TC- 1 in the plasma sheet. The magnetic holes detected by Cluster and TC-1 are located from $X \sim 7 R_{\mathrm{E}}$ to $X \sim 18 R_{\mathrm{E}}$. During the dipolarization process, the geomag- netic field lines in the near-Earth tail region are changed from tail-like to dipolar-like geometry (McPherron et al., 1973). Dipolarization not only affects the geometry of field lines, but also accompanies many other phenomena. Many previous works show that ions could be accelerated (e.g. Mauk, 1986; Zhou et al., 2010), and both the ion density and $\beta$ 
could increase several times after the dipolarization process (e.g. Zhang et al., 2007; Tang et al., 2009), which indicate that the $R$ value of plasma should increase. There are also many observations that show that the dipolarization process, coupled with electron acceleration and wave particle interactions, can account for electron heating (see, for example, Ashour-Abdalla et al., 2009; Fu et al., 2011). Ge et al. (2011) pointed out that the dipolarization process might provide a more anistropic plasma environment for the growth of mirror instability and their observations indicate that the magnetic holes might be linked to the dipolarization process itself. Our observations of most plasma sheet magnetic holes are not directly related to the dipolarization process as described in Ge et al. (2011), but in comparison with the randomly selected plasma sheet passes, the plasma sheet magnetic holes do seem to occur more often in a more dipolar magnetic field topology. So this suggests that these magnetic holes might have a close relationship with the dipolarization process.

The structures detected by Ge et al. (2011) occurred in a mirror stable environment. Our results also show that most magnetic holes detected by Cluster exist in a mirror stable environment. Inside the structures detected by Ge et al. (2011), the electron distribution was isotropic, while we found an enhancement of electron energy flux at a $90^{\circ}$ pitch angle in our cases. Since our observations were taken further down to the tail than those of Ge et al. (2011), the above difference might be a result of the different stages of evolution of the magnetic holes. In order to answer these questions, it is clear that the electron properties of magnetic holes require further investigation.

Scale sizes of plasma sheet magnetic holes, based on multi-spacecraft timing calculations of velocity and propagation at ion flow speed, indicates that most structures are smaller than the proton Larmor radius. Previous observations suggest the size of magnetic holes in the solar wind is typically about 10 times the size of their background proton Larmor radius. As Sect. 2.2.5 mentioned, the mirror instability might be excited in the plasma sheet. The finite electron temperature effect does not seem to alter the size of mirror mode structures significantly (Istomin et al., 2009); however, most of the plasma sheet magnetic holes occur in a marginally mirror stable environment. Therefore, whether these plasma sheet magnetic holes are generated by the mirror instability requires further investigation. From the increase in the perpendicular electron energy flux in the magnetic holes, it appears that magnetic holes in the plasma sheet have a close relationship with electrons. This raises the possibility that electron instabilities may play a part in the formation of these magnetic holes.

From Fig. 4a, b and c, we find that most magnetic holes detected by TC-1 seem to have a relatively larger scale size than those found by Cluster. From Fig. 7a and b, there are more events with magnetic holes detected by TC- 1 than those by Cluster with small $B_{\min } / B$ ratios, i.e. there are about $8.8 \%$ $(6 / 68)$ of the magnetic holes detected by Cluster with ratios smaller than 0.5 and about $19.5 \%$ (8/41), for TC- 1 . The distribution of the ratios for magnetic holes detected by Cluster with spin resolution magnetic field data is consistent with the above result. These results imply that magnetic holes detected by TC- 1 are more fully developed than those by Cluster. Figure $8 \mathrm{a}$ is the distribution of timing velocities in the $\mathrm{X}-\mathrm{Y}$ plane of the magnetic holes detected by Cluster. Figure $8 \mathrm{~b}$ and $\mathrm{c}$ are the distributions of their background plasma flow velocities measured by $\mathrm{C} 1$ and $\mathrm{C} 3$. From these three figures, we can see that most magnetic holes are propagating towards the Earth, as well as the magnetic holes detected by TC-1 (Fig. 8d). This observation suggests that the magnetic holes detected by Cluster might have propagated to the vicinity of the TC-1 orbit and that during this process, the magnetic holes have evolved further. The generation and evolution of these magnetic holes certainly need more detailed investigation.

The results of this research can be summarized as follows: statistical analysis has shown that for most plasma sheet magnetic holes, the background magnetic field $B_{\mathrm{Z}}$ is bigger than its $B_{\mathrm{X}}$ component and in comparison with the randomly selected plasma sheet passes, they seem to more favorably occur in a dipolar magnetic field topology. Thus, these magnetic holes might have a close relationship with the dipolarization process, though most plasma sheet magnetic holes do not associate with the dipolarization process as in Ge et al. (2011). It is suggested that the magnetic holes detected by Cluster might have propagated to the vicinity of the TC-1 orbit and during this process, the magnetic holes have further developed. These magnetic holes correspond to an enhancement of electron energy flux at a $90^{\circ}$ pitch angle. Most plasma sheet magnetic holes occur in a marginally mirror stable environment, but whether the plasma sheet magnetic holes are generated by the mirror instability or not is unknown. The scale sizes of magnetic holes are generally smaller than the background proton Larmor radius. The scale size of the holes and the electron energy flux enhancement within them suggest that the formation of plasma sheet magnetic holes has a link to the behavior of electrons rather than protons. Theories that link the electron behavior and the generation of this kind of small scale magnetic holes are not present in literature and need to be developed in the future.

Acknowledgements. The work is supported by NNSFC 41031065 , 41074106, and 40874086, the Shandong Natural Science Foundation (Grant No. 2009ZRB01352, JQ201112), IIFSDU 2010ZRJQ001, and by the Project Supported by the Specialized Research Fund for State Key Laboratories in China. MWD is partly supported by Chinese Academy of Sciences (CAS) visiting Professorship for senior international scientists grant no. 2009S1-54. We are grateful to B. Li (SDUWH, China), O. A. Pokhotelov (University of Sheffield, UK) and X. G. Wang (PKU, China) for their helpful discussions. Thanks to FGM, CIS, PEACE teams, and ESA CAA web for providing the Cluster and TC-1 data.

Guest Editor M. Taylor thanks two anonymous referees for their help in evaluating this paper. 


\section{References}

Ashour-Abdalla, M., Zhou, M., Schriver, D., El-Alaoui, M., Deng, X., Richard, R. L., Walker, R. J., and Sergeev, V. A.: Electron acceleration during substroms, American Geophysical Union, Fall Meeting, America, available at: http://adsabs.harvard.edu/abs/ 2009AGUFMSM53B1373A, 14-18 December 2009.

Balogh, A., Carr, C. M., Acuña, M. H., Dunlop, M. W., Beek, T. J., Brown, P., Fornacon, K.-H., Georgescu, E., Glassmeier, K.H., Harris, J., Musmann, G., Oddy, T., and Schwingenschuh, K.: The Cluster Magnetic Field Investigation: overview of in-flight performance and initial results, Ann. Geophys., 19, 1207-1217, doi:10.5194/angeo-19-1207-2001, 2001.

Baumgartel, K.: Soliton approach to magnetic holes, J. Geophys. Res.-Space Phys., 104, 28295-28308, doi:10.1029/1999JA900393, 1999.

Baumgartel, K., Sauer, K., and Dubinin, E.: Towards understanding magnetic holes: Hybrid simulations, Geophys. Res. Lett., 30, 4, doi:10.1029/2003GL017373, 2003.

Bavassano Cattaneo, M. B., Basile, C., Moreno, G., and Richardson, J. D.: Evolution of mirror structures in the magnetosheath of Saturn from the bow shock to the magnetopause, J. Geophys. Res., 103, 11961-11972, doi:10.1029/97JA03683, 1998.

Buti, B., Tsurutani, B. T., Neugebauer, M., and Goldstein, B. E.: Generation mechanism for magnetic holes in the solar wind, Geophys. Res. Lett., 28, 1355-1358, doi:10.1029/2000GL012592, 2001.

Carr, C., Brown, P., Zhang, T. L., Aydogar, O., Magnes, W., Auster, U., Balogh, A., Beek, T., Eichelberger, H., Fornacon, K. H., Georgescu, E., Gloag, J., Liao, H., Ludlam, M., Nakamura, R., O'Brien, H., Oddy, T., and Richter, I.: The Double Star magnetic field investigation: Overview of instrument performance and initial results, Adv. Space Res., 38, 1828-1833, 2006.

Cheng, C. Z. and Qian, Q.: Theory of ballooning-mirror instabilities for anisotropic pressure plasmas in the magnetosphere, J. Geophys. Res., 99, 11193-11209, doi:10.1029/94JA00657, 1994.

Crooker, N. U., Eastman, T. E., and Stiles, G. S.: Observations of plasma depletion in the magnetosheath at the dayside magnetopause, J. Geophys. Res., 84, 869-874, doi:10.1029/JA084iA03p00869, 1979.

Davidson, R. C. and Ogden, J. M.: Electromagnetic ion cyclotron instability driven by ion energy anisotropy in high-beta plasmas, Phys. Fluids, 18, 1045-1050, 1975.

Fu, H. S., Khotyaintsev, Y. V., Andre, M., and Vaivads, A.: Fermi and betatron acceleration of suprathermal electrons behind dipolarization fronts, J. Geophys. Res.-Space Phys., 38, L16104, doi:10.1029/2011GL048528, 2011.

Gary, S. P. and Karimabadi H.: Linear theory of electron temperature anisotropy instabilities: Whistler, mirror, and Weibel, J. Geophys. Res-Space Phys., 111, A11224, doi:10.1029/2006JA011764, 2006.

Gary, S. P., Montgomery, M. D., Feldman, W. C., and Forslund, D. W.: Proton temperature anisotropy instabilities in the solar wind, J. Geophys. Res., 81, 1241-1246, doi:10.1029/JA081i007p01241, 1976.

Ge, Y. S., McFadden, J. P., Raeder, J., Angelopoulos, V., Larson, D., and Constantinescu, O. D.: Case studies of mirror-mode structures observed by THEMIS in the nearEarth tail during substorms, J. Geophys. Res., 116, A01209, doi:10.1029/2010JA015546, 2011.
Génot, V., Schwartz, S. J., Mazelle, C., Balikhin, M., Dunlop, M., and Bauer, T. M.: Kinetic study of the mirror mode, J. Geophys. Res.-Space Phys., 106, 21611-21622, doi:10.1029/2000JA000457, 2001.

Génot, V., Budnik, E., Hellinger, P., Passot, T., Belmont, G., Trávn'ıček, P. M., Sulem, P.-L., Lucek, E., and Dandouras, I.: Mirror structures above and below the linear instability threshold: Cluster observations, fluid model and hybrid simulations, Ann. Geophys., 27, 601-615, doi:10.5194/angeo-27-601-2009, 2009.

Hasegawa, A.: Drift mirror instability in the magnetosphere, Phys. Fluids, 12, 2642-2650, doi:10.1063/1.1692407,1969.

Hellinger, P.: Comment on the drift mirror instability. Phys. Plasmas, 15, 2008.

Istomin, Y. N., Pokhotelov, O. A., and Balikhin, M. A.: Nonzero electron temperature effects in nonlinear mirror modes, Phys. Plasmas, 16, 5, doi:10.1063/1.3275787, 2009.

Johnstone, A. D., Alsop, C., Burge, S., Carter, P. J., Coates, A. J., Coker, A. J., Fazakerley, A. N., Grande, M., Gowen, R. A., Gurgiolo, C., Hancock, B. K. Narheim, B., Preece, A., Sheather, P. H., Winningham, J. D., Woodliffe, R. D.: PEACE: a Plasma Electron And Current Experiment, Space Sci. Rev., 79, 351-398, doi:10.1023/A:1004938001388, 1997.

Kaufmann, R. L., Horng, J. T., and Wolfe, A.: Large-amplitude hydromagnetic waves in the inner magnetosheath, J. Geophys. Res., 75, 4666-4676, doi:10.1029/JA075i025p04666, 1970.

Liu, Y. C. M., Lee, M. A., and Kucharek, H.: A quasilinear theory of ion "thermalization" and wave excitation downstream of Earth's bow shock, J. Geophys. Res.-Space Phys., 110, A09101, doi:10.1029/2005JA011096, 2005.

Mauk, B. H.: Quantitative Modeling of the "Convection Surge" Mechanism of Ion Acceleration, J. Geophys. Res., 91, 1342313431, doi:10.1029/JA091iA12p13423, 1986.

McPherron, R. L., Russell, C. T., and Aubry, M. P.: Satellite studies of magnetospheric substorms on August 15, 1968. IX. Phenomenological model for substorms, J. Geophys. Res., 78, 31313149, 1973.

Paschmann, G. and Daly P. W. (Eds.): Analysis Methods for MultiSpacecraft Data, Eur. Space Agency, Noordwijk, The Netherlands, 1998.

Pokhotelov, O. A., Balikhin, M. A., Alleyne, H. S., and Onishchenko, O. G.: Mirror instability with finite electron temperature effects, J. Geophys. Res-Space Phys., 105, 2393-2401, 2000.

Pokhotelov, O. A., Onishchenko, O. G., Balikhin, M. A., Treumann, R. A., and Pavlenko, V. P.: Drift mirror instability in space plasmas, 2, Nonzero electron temperature effects, J. Geophys. ResSpace Phys., 106, 13237-13246, 2001.

Rae, I. J., Mann, I. R., Watt, C. E. J., and Kistler, L. M.: Equator$\mathrm{S}$ observations of drift mirror mode waves in the dawnside magnetosphere, J. Geophys. Res.-Space Phys., 112, A11203, doi:10.1029/2006JA012064, 2007.

Rème, H., Aoustin, C., Bosqued, J. M., Dandouras, I., Lavraud, B., Sauvaud, J. A., Barthe, A., Bouyssou, J., Camus, Th., CoeurJoly, O., Cros, A., Cuvilo, J., Ducay, F., Garbarowitz, Y., Medale, J. L., Penou, E., Perrier, H., Romefort, D., Rouzaud, J., Vallat, C., Alcaydé, D., Jacquey, C., Mazelle, C., d'Uston, C., Möbius, E., Kistler, L. M., Crocker, K., Granoff, M., Mouikis, C., Popecki, M., Vosbury, M., Klecker, B., Hovestadt, D., Kucharek, H., 
Kuenneth, E., Paschmann, G., Scholer, M., Sckopke, N., Seidenschwang, E., Carlson, C. W., Curtis, D. W., Ingraham, C., Lin, R. P., McFadden, J. P., Parks, G. K., Phan, T., Formisano, V., Amata, E., Bavassano-Cattaneo, M. B., Baldetti, P., Bruno, R., Chionchio, G., Di Lellis, A., Marcucci, M. F., Pallocchia, G., Korth, A., Daly, P. W., Graeve, B., Rosenbauer, H., Vasyliunas, V., McCarthy, M., Wilber, M., Eliasson, L., Lundin, R., Olsen, S., Shelley, E. G., Fuselier, S., Ghielmetti, A. G., Lennartsson, W., Escoubet, C. P., Balsiger, H., Friedel, R., Cao, J.-B., Kovrazhkin, R. A., Papamastorakis, I., Pellat, R., Scudder, J., and Sonnerup, B.: First multispacecraft ion measurements in and near the Earth's magnetosphere with the identical Cluster ion spectrometry (CIS) experiment, Ann. Geophys., 19, 1303-1354, doi:10.5194/angeo19-1303-2001, 2001.

Rème, H., Dandouras, I., Aoustin, C., Bosqued, J. M., Sauvaud, J. A., Vallat, C., Escoubet, P., Cao, J. B., Shi, J., BavassanoCattaneo, M. B., Parks, G. K., Carlson, C. W., Pu, Z., Klecker, B., Moebius, E., Kistler, L., Korth, A., Lundin, R., and the HIA team: The HIA instrument on board the Tan Ce 1 Double Star near-equatorial spacecraft and its first results, Ann. Geophys., 23, 2757-2774, doi:10.5194/angeo-23-2757-2005, 2005.

Russell, C. T., Mellott, M. M., Smith, E. J., King, J. H.: Multipoint spacecraft observations of interplanetary shocks: Four spacecraft determination of shock normals, J. Geophys. Res., 88, 47394748, 1983.

Russell, C. T., Riedler, W., Schwingenschuh, K., and Yeroshenko, Ye,: Mirror instability in the magnetosphere of Comet Halley, Geophys. Res. Lett., 14, 644-647, 1987.

Russell, C. T., Kivelson, M. G., Khurana, K. K., and Huddleston, D. E.: Magnetic fluctuations close to Io: ion cyclotron and mirror mode wave properties, Planet Space Sci., 47, 143-150, 1999.

Russell, C. T., Jian, L. K., Luhmann, J. G., Zhang, T. L., Neubauer, F. M., Skoug, R. M., Blanco-Cano, X., Omidi, N., and Cowee, M. M.: Mirror mode waves: Messengers from the coronal heating region, Geophys. Res. Lett., 35, L15101, doi:10.1029/2008GL034096, 2008.

Sergeev, V., Runov, A., Baumjohann, W., Nakamura, R., Zhang, T. L., Balogh, A., Louarnd, P., Sauvaud, J. A., and Reme, H.: Orientation and propagation of current sheet oscillations, Geophys. Res. Lett., 31, L05807, doi:10.1029/2003GL019346, 2004.

Shi, Q. Q., Shen, C., Pu, Z. Y., Dunlop, M.W., Zong, Q.-G., Zhang, H., Xiao, C. J., Liu, Z. X., and Balogh, A.: Dimensional analysis of observed structures using multipoint magnetic field measurements: Application to Cluster, Geophys. Res. Lett., 32, L12105, doi:10.1029/2005GL022454, 2005.

Shi, Q. Q., Shen, C., Dunlop, M. W., Pu, Z. Y., Zong, Q.-G., Liu, Z. X., Lucek, E., and Balogh, A.: Motion of observed structures calculated from multi-point magnetic ?eld measurements: Application to Cluster, Geophys. Res. Lett., 33, L08109, doi:10.1029/2005GL025073, 2006.

Shi, Q. Q., Pu, Z. Y., Soucek J., Zong, Q.-G., Fu, S.Y., Xie, L., Chen, Y., Zhang, H., Li, L., Xia, L.D., Liu, Z.X., Lucek, E., Fazakerley, A. N., and Reme, H.: Spatial structures of magnetic depression in the Earth's high-altitude cusp: Cluster multipoint observations, J. Geophys. Res., 114, A10202, doi:10.1029/2009JA014283, 2009a.

Shi, Q. Q., Zong, Q.-G., Zhang, H., Pu, Z. Y., Fu, S. Y., Xie, L., Chen, Y., Li, L., Xia, L. D., Liu, Z. X., Fazakerley, A. N., Reme, H., and Lucek, E.: Cluster observations of the entry layer equatorward of the cusp under northward interplanetary magnetic field, J. Geophys. Res., 114, A12219, doi:10.1029/2009JA014475, 2009b.

Soucek, J. and Escoubet, C. P.: Cluster observations of trapped ions interacting with magnetosheath mirror modes, Ann. Geophys., 29, 1049-1060, doi:10.5194/angeo-29-1049-2011, 2011.

Soucek, J., Lucek, E., and Dandouras, I.: Properties of magnetosheath mirror modes observed by Cluster and their response to changes in plasma parameters, J. Geophys. Res.-Space Phys., 113, A04203, doi:10.1029/2007ja012649, 2008.

Southwood, D. J. and Kivelson, M. G.: Mirror instability. 1. Physical mechanism of linear instability, J. Geophys. Res., 98, 91819187, 1993.

Sperveslage, K., Neubauer, F. M., Baumgrtel, K., and Ness, N. F.: Magnetic holes in the solar wind between $0.3 \mathrm{AU}$ and $17 \mathrm{AU}$, Nonlin. Processes Geophys., 7, 191-200, doi:10.5194/npg-7191-2000, 2000.

Sun, W. J., Shi, Q. Q., Fu, S. Y., Zong, Q. G., Pu, Z. Y., Xie, L., Xiao, T., Li, L., Liu, Z. X., Reme, H., and Lucek, E.: Statistical research on the motion properties of the magnetotail current sheet: Cluster observations, Sci. China-Technol. Sci., 53, 1732 1738, 2010.

Tang, C. L., Li, Z. Y., Angelopoulos, V., Mende, S. B., Glassmeier, K. H., Donovan, E., Russell, C. T., and Lu, L.: THEMIS observations of the near-Earth plasma sheet during a substorm, J. Geophys. Res.-Space Phys., 114, A09211, doi:10.1029/2008ja013729, 2009.

Travnicek, P., Hellinger, P., Taylor, M., Escoubet, C. P., Dandouras, I., and Lucek, E.: Magnetosheath plasma expansion: Hybrid simulations, Geophys. Res. Lett., 34, L15104, doi:10.1029/2007g1029728, 2007.

Tsurutani, B. T., Smith, E. J., Anderson, R. R., Ogilvie, K. W., Scudder, J. D., Baker, D. N., and Bame, S. J.: Lion roars and nonoscillatory drift mirror waves in the magnetosheath, J. Geophys. Res., 87, 6060-6072, 1982.

Tsurutani, B. T., Guarnieri, F. L., Lakhina, G. S., and Hada, T.: Rapid evolution of magnetic decreases (MDs) and discontinuities in the solar wind: ACE and Cluster, Geophys. Res. Lett., 32, L10103, doi:10.1029/2004g1022151, 2005.

Tsurutani, B. T., Lakhina, G. S., Verkhoglyadova, O. P., Echer, E., Guarnieri, F. L., Narita, Y., and Constantinescu, D. O.: Magnetosheath and heliosheath mirror mode structures, interplanetary magnetic decreases, and linear magnetic decreases: Differences and distinguishing features. J. Geophys. Res.-Space Phys., 116, A02103, doi:10.1029/2010JA015913, 2011.

Turner, J. M., Burlaga, L. F., Ness, N. F., Lemaire, J. F.: Magnetic holes in the solar wind, J. Geophys. Res., 82, 1921-1924, 1977.

Volwerk, M., Zhang, T. L., Delva, M., Voros, Z., Baumjohann, W., and Glassmeier, K. H.: First identification of mirror mode waves in Venus' magnetosheath?, Geophys. Res. Lett., 35, E00b16, doi:10.1029/2008je003154, 2008a.

Volwerk, M., Zhang, T. L., Delva, M., Voros, Z., Baumjohann, W., and Glassmeier, K. H.: Mirror-mode-like structures in Venus' induced magnetosphere, J. Geophys. Res.-Planets, 113, L12204, doi:10.1029/2008gl033621, 2008b.

Walsh, A. P., Owen, C. J., Fazakerley, A. N., Forsyth, C., and Dandouras, I.: Average magnetotail electron and proton pitch angle distributions from Cluster PEACE and CIS observations, Geophys. Res. Lett., 38, L06103, doi:10.1029/2011g1046770, 2011. 
Winterhalter, D., Neugebauer, M., Goldstein, B. E., Smith, E. J., Bame, S. J., and Balogh, A.: Ulysses field and plasma observations of magnetic holes in the solar wind and their relation to mirror-mode structures, J. Geophys. Res., 99, 23371-23381, 1994.

Winterhalter, D., Neugebauer, M., Goldstein, B. E., Smith, E. J., Tsurutani, B. T., Bame, S. J., and Balog, A.: Magnetic holes in the solar wind and their relation to mirror-mode structure, Space Sci. Rev., 77, 201-204, 1995.

Xiao, T., Shi, Q. Q., Zhang, T. L., Fu, S. Y., Li, L., Zong, Q. G., $\mathrm{Pu}, \mathrm{Z}$. Y., Xie, L., Sun, W. J., Liu, Z. X., Lucek, E., and Reme, H.: Cluster-C1 observations on the geometrical structure of linear magnetic holes in the solar wind at $1 \mathrm{AU}$, Ann. Geophys., 28, 1695-1702, doi:10.5194/angeo-28-1695-2010, 2010.

Zhang, H., Pu, Z. Y., Cao, X., Fu, S. Y., Liu, Z. X., Ma, Z. W., Dunlop, M. W., Baumjohann, W., Xiao, C. J., Hong, M. H., Cao, J. B., Zong, Q. G., Wang, X. G., Carr, C., Reme, H. A., Dandouras, I., Fazakerley, A., Frey, H. U., and Escoubet, C. P.: TC-1 observations of flux pileup and dipolarization-associated expansion in the near-Earth magnetotail during substorms, Geophys. Res. Lett., 34, L03104, doi:10.1029/2006g1028326, 2007.
Zhang, T. L., Russell, C. T., Baumjohann, W., Jian, L. K., Balikhin, M. A., Cao, J. B., Wang, C., Blanco-Cano, X., Glassmeier, K.-H., Zambelli, W., Volwerk, M., Delva, M., and Voros, Z.: Characteristic size and shape of the mirror mode structures in the solar wind at $0.72 \mathrm{AU}$, Geophys. Res. Lett., 35, L10106, doi:10.1029/2008GL033793, 2008.

Zhang, T. L., Baumjohann,W., Russell, C. T., Jian, L. K., Wang, C., Cao, J. B., Balikhin, M., Blanco-Cano, X., Delva, M., and Volwerk, M.: Mirror mode structures in the solar wind at 0.72AU, J. Geophys. Res., 114, A10107, doi:10.1029/2009JA014103, 2009.

Zhou, X. Z., Angelopoulos, V., Sergeev, V. A., and Runov, A.: Accelerated ions ahead of earthward propagating dipolarization fronts, J. Geophys. Res-Space Phys., 115, A00i03, doi:10.1029/2010ja015481, 2010. 